\title{
Cefaclor monohydrate loaded microemulsion formulation for topical application: Characterization with new developed UPLC method and stability study
}

\author{
A. Alper ÖZTÜRK 1 * (D) , Umay Merve GÜVEN 2 (D)
}

1 Department of Pharmaceutical Technology, Faculty of Pharmacy, Anadolu University, Eskişehir, Turkey.

2 Department of Pharmaceutical Technology, Faculty of Pharmacy, Çukurova University, Adana, Turkey.

* Corresponding Author. E-mail: aaozturk@anadolu.edu.tr (A.A.Ö.); Tel. +90-222-335 05 80/3731.

Received: 01 November 2018 / Revised: 26 November 2018 / Accepted: 27 November 2018

\begin{abstract}
The purpose of this study was to formulate Cefaclor monohydrate (CEF) loaded microemulsion formulations with the help of pseudo-ternary phase diagrams for topical application. Additionally, in this study also a new ultra-performance liquid chromatography (UPLC) method was developed for the determination of CEF, which was not previously entered into the literature. The droplet size, polydispersity index, $\mathrm{pH}$, rheology, drug content, FTIR, dissolution study and release kinetic study have been used in the characterization of microemulsion. The UPLC method developed was validated for linearity, specificity, precision, sensitivity, accuracy, range and robustness. Linearity was determined to be at a concentration range of 5-55 $\mu$ g. $\mathrm{mL}^{-1}$. The method developed was decided to be precise due to RSD values of $<2 \%$. Recovery of the method was satisfactory owing to $<2 \%$ RSD value. The drug content was found to be in the range of $99.54-100.01 \%$ in stability study, indicating the uniformity of the high drug content. The release of CEF from microemulsion showed conformity with the zero-order kinetics. The droplet size of the formulations were measured ranged in 170.6-174.4 $\mathrm{nm}$. The droplet size distribution of the formulations were observed range in 0.154-0.150. The results showed that nano-sized and monodisperse formulations were prepared. The storage stability of CEF loaded optimum microemulsion was followed to ICH Q1(R2) at $25 \pm 1^{\circ} \mathrm{C} / 60 \% \pm 5 \%$ relative humidity up to sixmonths. As a result of the stability study, microemulsion was found to be physically and chemically stable. According to the results, microemulsion formulation prepared have longer release times than the release of pure CEF.
\end{abstract}

KEYWORDS: Cefaclor monohydrate; UPLC; microemulsion; stability study.

\section{INTRODUCTION}

Cephalosporins are a group of bactericidal semi-synthetic beta-lactam antibiotic drug active ingredients that containing four generations of compounds grouped by pharmacokinetic / pharmacodynamic and microbiological properties. This group is widely used worldwide in the treatment of human and veterinary diseases [1]. The group of cephalosporin's, which are less allergenic than penicillin's and less sensitive to betalactamases, are considered broad-spectrum antibiotics used against both gram-negative and positive bacterial strains and effectively break in microbial growth [1,2]. Cephalosporins can be administered orally and parenterally. They show rapid distribution in biological systems and have half-lives ranging from 0.25 to 9 hours [2]. Cefaclor monohydrate (CEF) belongs to semisynthetic cephalosporin antibiotic group for oral administration. The chemical name and molecular formula of CEF is 3-Chloro-7-d-(2-phenylglycinamido)-3cephem-4-carboxylic acid monohydrate and $\mathrm{C}_{15} \mathrm{H}_{14} \mathrm{ClN}_{3} \mathrm{O}_{4} \mathrm{~S}$, respectively. Figure 1 shown chemical structure of CEF.<smiles>NC(C(=O)NC1C(=O)N2C(C(=O)O)=C(Cl)CS[C@H]12)c1ccccc1</smiles>

Figure 1. Chemical structure of CEF.

How to cite this article: Öztürk AA, Güven UM. Cefaclor monohydrate loaded microemulsion formulation for topical application: Characterization with new developed UPLC method and stability study. J Res Pharm. 2019; 23(3): 426-440. 
Mean serum levels of 7, 13 and $23 \mu \mathrm{g} . \mathrm{mL}^{-1}$ averaged over 30 to 60 minutes after oral doses of $0.25 \mathrm{~g}$, 0.5 $\mathrm{g}$ and $1 \mathrm{~g}$ on an empty stomach, respectively. A large part of the drug is thrown from the body in first 2 hours after oral administration of CEF. In normal subjects without an antimicrobial disease the serum half-life varies between 0.6 and 0.9 hours. The plasma half-life of this molecule is 2.3 to 2.8 hours in the literature [4].

Ultra-performance liquid chromatography (UPLC) system operates with sub-2 micron chromatographic particles at pressures in the of 6000-15000 psi range. The reduction in particle size to below 2 micron provide improved chromatographic resolution and more optimal responses compared to conventional High performance liquid chromatography (HPLC) with larger particles. UPLC also provides a better and wider range of linear speed, velocities, faster analysis time and better chromatographic resolution. High chromatographic resolution, resulting in increased signal to noise ratio and narrow peak width compared to conventional HPLC, is useful not only for drug formulations, but also to allow for the identification of a large number of metabolites at the physiological level [5]. As a result, it can be said that UPLC offers important advantages over traditional reversed phase HPLC (RP-HPLC), with two quartets peak capacity, almost ten times faster in speed and three to five times greater sensitivity compared to the conventional 3.5-micron stationary phase [6]. As noted earlier, it is in the literature that UPLC results in 20\% more detectable components compared to HPLC for separation of human serum metabolites [7]. CEF is officially in the European Pharmacopoeia (EP-2014), the United States Pharmacopoeia (USP-NF 33-2015) and the British Pharmacopoeia (BP-2017). The HPLC methods developed for CEF are available in these pharmacopoeias [4]. While many HPLC methods for CEF have been introduced into the literature; a simple, precise, specific and highly sensitive \& accurate UPLC method is not yet available [4, 8-10].

Microemulsions (MEs) are drug delivery systems that have recently attracted attention in drug research and development studies. MEs are high thermodynamically and kinetically stable, optical transparent, low viscosity and isotropic system comprising a water phase, an oil phase and a surfactant and usually together with a co-surfactant. According to the preparation method, ME systems are separated into oil in water $(\mathrm{O} / \mathrm{W})$, water in oil (W/O) and bicontinuous ME. In the literature, many studies have been conducted to demonstrate the improved bioavailability of drugs when using ME. Various ME systems with surfactants and oils have the advantages of a large surface area required for transport of drugs in the gastrointestinal tract and topical way for low free energy and absorption. As a result, MEs have been proposed to positively influence drug absorption in a variety of ways, including protecting the drug from oxidative and enzymatic degradation and enhancing membrane permeability and lymphatic transport, and have also been suggested to prolong drug release in oral use [11, 12]. Another important issue of ME is topical application. The small droplet size of ME provides a large surface area and uniform distribution on the skin, film formation, perfect occlusiveness, aesthetic qualities and skin feel. MEs may increase the penetration of the drug active substance into the skin by a number of mechanisms. They provide high dissolution capacity for both hydrophilic and lipophilic drug active substance, so increasing the loading capacity and dosing of the formulation. MEs provide good surface contact with the surface of the stratum corneum, coupled with large surface area and good skin contact, obstructive nature. The oil and surfactant in the microemulsion formulation have a direct penetration enhancing effect on the lipid structure of the stratum corneum [13].

In this study, CEF loaded topical microemulsion formulations were prepared and characterized for droplet size, polydispersity index, $\mathrm{pH}$, rheology, FT-IR, drug content, dissolution study and release kinetics study with DDSolver software program. A new UPLC method, which was not previously reported in the literature, has been developed and validated. This method was used for the determination of CEF in the new formulation and dissolution study. In the last part of the study, a 6-month stability study was performed on the selected optimum microemulsion formulation.

\section{RESULTS AND DISCUSSION}

\subsection{Method optimization}

The optimization of chromatographic separation for analysis of CEF, have been started by testing some parameters such as particle size of stationary phase, column length, temperature, flow rate and the composition of the mobile phase. For this purpose, firstly, two different size $\mathrm{C}_{18}$ columns $(2.1 \times 50 \mathrm{~mm}$ and 2.1 $\mathrm{x} 100 \mathrm{~mm}$ ) which has $1.8 \mu \mathrm{m}$ particle size were tested with different compositions of water and methanol as mobile phase. Since, suitable retention time was obtained with short column, the study was continued with $2.1 \times 50 \mathrm{~mm} \mathrm{C}_{18}$ column. Because the peak symmetry was not smooth, buffer solution was added to the mobile phase mixture. After this step, different buffer systems (acetate buffer, disodium hydrogen phosphate buffer, potassium dihydrogen phosphate buffer) were added to the mobile phase mixture. In terms of peak 
morphology and retention time, it was decided that the most appropriate buffer was acetate buffer. Thus, after selecting acetate buffer, different concentrations $(0.05,0.1,0.2,0.3,0.4$ and $0.5 \mathrm{M})$ were tested, and $0.1 \mathrm{M}$ was selected as the optimum buffer concentration. After all this steps, mobile phase composition was determined as methanol: water: $0.1 \mathrm{M}$ acetate buffer (40:50:10, v/v/v). At this stage, flow rates of 0.1 to $0.5 \mathrm{~mL} . \mathrm{min}^{-1}$ were tried to be observed, with careful consideration of peak morphology and retention time. When the flow rate was reduced, expansion at the peak base was observed. When the flow rate was increased, the active substance peak was observed at 0.6 minutes and coincided with the mobile phase peak. These conditions were overcome with a flow rate of $0.25 \mathrm{~mL} \cdot \mathrm{min}^{-1}$. In terms of retention time, $25^{\circ} \mathrm{C}, 30^{\circ} \mathrm{C}, 35^{\circ} \mathrm{C}$ and $40^{\circ} \mathrm{C}$ were tested and $40^{\circ} \mathrm{C}$ was found to be the most suitable colon temperature. When operating the instrument under these conditions, chromatograms were examined at different absorbance's and the wavelength at which the maximum absorbance was observed was chosen as $265 \mathrm{~nm}$. The best chromatographic separation occurred on $\mathrm{C}_{18}(2.1 \times 50$ $\mathrm{mm}, 1.8 \mu \mathrm{m}$ ) with a mobile phase consisting methanol: water: $0.1 \mathrm{M}$ acetate buffer at a flow rate of $0.25 \mathrm{~mL}$ $\mathrm{min}^{-1}$ and wavelength at $265 \mathrm{~nm}$. Table 1 shows the UPLC methodology applied for selected method.

Table 1. Summary conditions of the UPLC method.

\begin{tabular}{ll}
\hline Device & Agilent Technology 1290 Infinity \\
Column & Zorbax Eclipse Plus $\mathrm{C}_{18}(2.1 \times 50 \mathrm{~mm}, 1.8 \mu \mathrm{m})$ \\
Mobile phase & $40: 50: 10(\mathrm{v} / \mathrm{v} / \mathrm{v})$ methanol: water: $0.1 \mathrm{M}$ acetate buffer \\
Oven temperature & $40^{\circ} \mathrm{C}$ \\
Flow rate & $0.25 \mathrm{~mL} \cdot \mathrm{min}^{-1}$ \\
İnjection volume & $0.5 \mu \mathrm{L}$ \\
Wavelength & $265 \mathrm{~nm}$ \\
Retention time & $1.6 \mathrm{~min}$ \\
\hline
\end{tabular}

\subsection{Method validation}

Method validation studies for CEF were carried out according to the literature and International Conference on Harmonization (ICH) guideline Q2(R1) $[14,15,16]$. Linearity of CEF for the method used was found to be $5-55 \mu \mathrm{g} \cdot \mathrm{mL}^{-1}$ while regression equation was determined to be $\mathrm{y}=1.5931 \mathrm{x}-1.6058$ by plotting concentration $(\mathrm{x})$ versus normalized peak area ratio $(\mathrm{y})$. Determination coefficient $\left(\mathrm{R}^{2}\right)$ of 0.9999 was highly significant. Linearity test results are shown in Table 2 and regression curve is presented in Figure 2. Range is the interval between the upper and lower concentration of active agent that have been indicated to be determined with precision, accuracy and linearity using the method as written. The accuracy and precision of the method are within the acceptable range [15]. In this study the range was observed linearly to the highest concentration $\left(220 \mu \mathrm{g} \cdot \mathrm{mL}^{-1}, \mathrm{R}^{2}: 0.9999\right)$.

Table 2. Series and area values prepared for linearity and range study.

\begin{tabular}{ccccccc}
\hline $\begin{array}{c}\text { CONC } \\
\left(\mu \mathrm{g} . \mathrm{mL}^{-1}\right)\end{array}$ & SET 1 & SET 2 & SET 3 & Mean & SD & SE \\
\cline { 2 - 7 } & 9.95 & 10.37 & 8.71 & 9.68 & 0.86 & 0.50 \\
$\mathbf{5 . 0 0}$ & 26.13 & 25.77 & 25.52 & 25.81 & 0.31 & 0.18 \\
$\mathbf{1 5 . 0 0}$ & 40.39 & 42.83 & 40.38 & 41.20 & 1.41 & 0.81 \\
$\mathbf{2 5 . 0 0}$ & 56.21 & 58.65 & 56.06 & 56.98 & 1.45 & 0.84 \\
$\mathbf{3 5 . 0 0}$ & 72.49 & 75.67 & 70.90 & 73.02 & 2.43 & 1.40 \\
$\mathbf{4 5 . 0 0}$ & 90.74 & 91.99 & 86.40 & 89.71 & 2.94 & 1.69 \\
$\mathbf{5 5 . 0 0}$ & 134.63 & 135.74 & 132.82 & 134.40 & 1.47 & 1.21 \\
$\mathbf{8 2 . 5 0}$ & 156.72 & 160.91 & 159.64 & 159.09 & 2.15 & 1.47 \\
$\mathbf{9 6 . 2 5}$ & 177.88 & 179.15 & 180.91 & 179.31 & 1.52 & 1.23 \\
$\mathbf{1 1 0 . 0 0}$ & 358.12 & 359.14 & 360.36 & 359.21 & 1.12 & 1.06 \\
$\mathbf{2 2 0 . 0 0}$ & & & & & & \\
\hline
\end{tabular}

*CONC: Concentration, ${ }^{* *}$ Area/Rt: Normalized peak area ratio. 


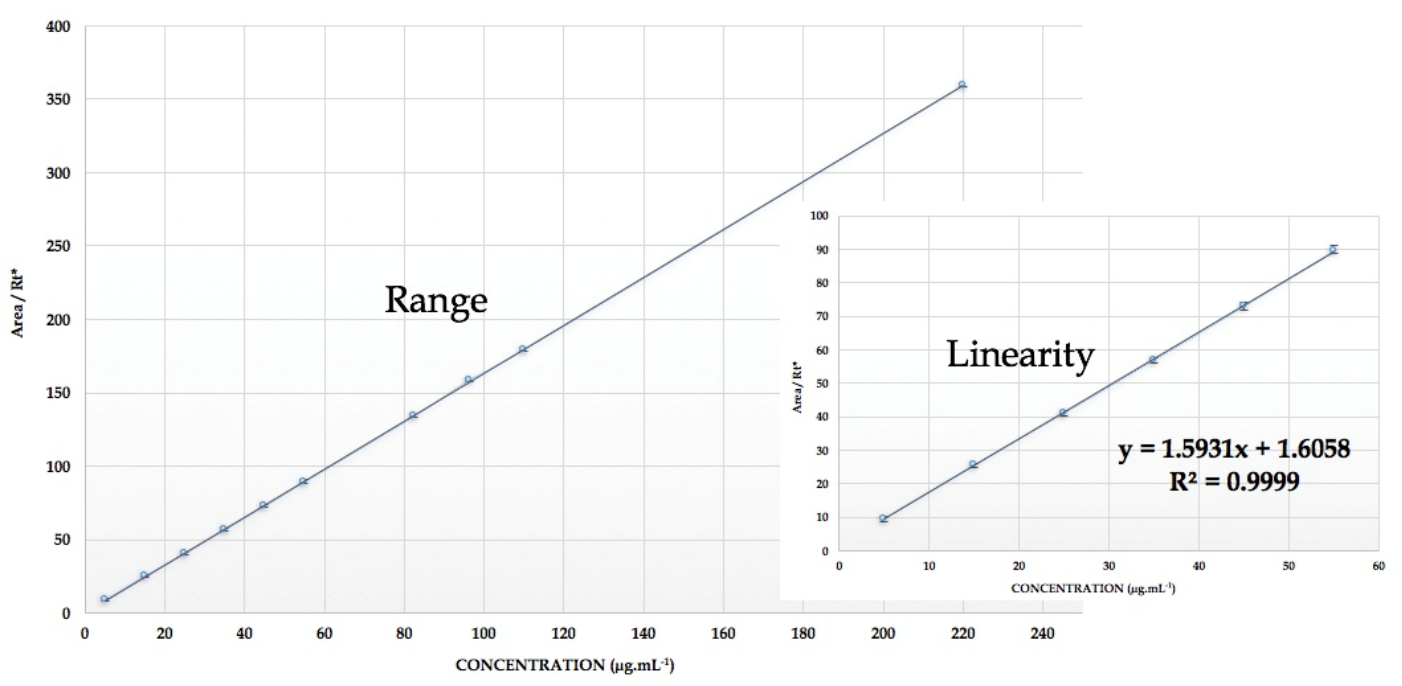

Figure 2. Regression profile of CEF (*Area/Rt: Normalized peak area ratio).

The ability to detect and measure is important performance characteristics of each measurement process. A representative feature of any analytical method developed; it can be defined as the smallest concentration that can be detected or quantified with a certain degree of precision [17]. In general, a limit of detection (LOD) is detected as the lowest concentration in a sample under the conditions specified in the test, but is not considered to be quantifiable. Limit of quantitation (LOQ) is the lowest concentration of an analyte in a test and can be determined with acceptable precision and accuracy under the specified test conditions. Detection and quantification limits are the two principal components of method validation [15]. In this study, LOD and LOQ were calculated by linear regression and found as $0.582 \mu \mathrm{g} \cdot \mathrm{mL}^{-1}$ and $1.765 \mu \mathrm{g} \cdot \mathrm{mL}^{-1}$ respectively.

Results of intermediate precision and repeatability tests on different concentrations are given in Table 3. RSD values for both intermediate precision and repeatability were $<2 \%$. Therefore, the method developed for CEF was found to be precise according to the suggestions in ICH Q2(R1) guidelines [16].

As shown in Table 3 perfect recoveries of CEF at various concentrations were obtained between 99.699 - $100.015 \%$ and also RSD values for all concentration were $<2 \%$. Table 3 indicates good accuracy of the UPLC method developed in this study.

Results were obtained for area response and retention time, RSD \% was calculated and examined for robustness. RSD \% for retention time for six different conditions were between 0.18 and $0.64 \%$ (Table 3 ), which is well inside the proposed acceptance basis of $\leq 5 \%$. RSD \% for area response was from 0.15 to $0.87 \%$, which also passed the proposed acceptance basis of $\leq 2 \%$ [15]. Therefore, it can be concluded that the method is consistent in front of the wavelength, temperature and flow rate.

The selectivity of the analytical method developed is very important for pharmaceutical technology. There are many excipients in the formulations developed and the peaks of these materials are not in conflict with the active substance in the chromatogram. Furthermore, in the characterization method of formulations such as in vitro dissolution study, they should not disturb the peak of the active substance in the medium used. It is noted that the substances in the medium used do not coincide with the chromatogram of the active substance. Characteristic UPLC chromatogram of CEF is given at Figure 3. It can be seen that chromatogram recorded for the combination of non-functioning components exposed no peaks at retention time of 1.6 minutes (Figure 3).

\subsection{Preparation of microemulsion formulation}

The substances to be used in the microemulsion formulation were selected carefully. Isopropyl myristate (IPM) is often used as an oil phase [18,19]. In addition to previous reports also confirmed that IPM was an excellent enhancer for transdermal delivery [20,21]. Appropriate excipient selection and safety evaluation especially of the co-surfactants is crucial in the formulation of microemulsions. Generally nonionic surfactants are chosen because of their good cutaneous tolerance, lower irritation potential and toxicity. There is wide use of nonionic surfactants in topical microemulsion formulations as solubilizing agents. Span 80 and Tween 80 were preferred as surfactants in system. Another important parameter in the formulation of 
microemulsion system is the choice of co-surfactants. In permeability studies, Propylene glycol was found to enhance penetration. Due to this property, it has been used as a cosurfactant in the formulation [18, 22].

Table 3. Precision, accuracy and robustness study results.

\section{PRECISION RESULTS}

\begin{tabular}{|c|c|c|c|c|c|}
\hline \multicolumn{3}{|c|}{ Area/Rt* } & \multicolumn{3}{|c|}{ Concentration $\left(20 \mu \mathrm{g} \cdot \mathrm{mL}^{-1}\right)$} \\
\hline 1st day & 2nd day & 3rd day & 1st day & 2nd day & 3rd day \\
\hline 33.465 & 33.202 & 33.729 & 19.999 & 19.833 & 20.164 \\
\hline 33.927 & 33.399 & 33.498 & 20.289 & 19.958 & 20.019 \\
\hline 33.796 & 33.564 & 33.432 & 20.206 & 20.061 & 19.978 \\
\hline \multicolumn{3}{|l|}{ Mean } & 20.165 & 19.951 & 20.054 \\
\hline \multicolumn{3}{|c|}{ Standard deviation (SD) } & 0.149 & 0.114 & 0.098 \\
\hline \multicolumn{3}{|c|}{ Coefficient of variation (CV) } & 0.740 & 0.571 & 0.488 \\
\hline \multicolumn{3}{|c|}{$95 \%$ confidence interval } & 0.371 & 0.283 & 0.243 \\
\hline & Area/Rt* & & \multicolumn{3}{|c|}{ Concentration $\left(30 \mu \mathrm{g} . \mathrm{mL}^{-1}\right)$} \\
\hline 1st day & 2nd day & 3rd day & 1st day & 2nd day & 3rd day \\
\hline 49.208 & 49.506 & 49.604 & 29.881 & 30.068 & 30.130 \\
\hline 48.824 & 49.703 & 49.357 & 29.640 & 30.192 & 29.975 \\
\hline 49.455 & 49.109 & 49.356 & 30.036 & 29.819 & 29.974 \\
\hline \multicolumn{3}{|l|}{ Mean } & 29.852 & 30.026 & 30.026 \\
\hline \multicolumn{3}{|c|}{ Standard deviation (SD) } & 0.200 & 0.190 & 0.090 \\
\hline \multicolumn{3}{|c|}{ Coefficient of variation (CV) } & 0.669 & 0.633 & 0.299 \\
\hline \multicolumn{3}{|c|}{$95 \%$ confidence interval } & 0.496 & 0.472 & 0.223 \\
\hline & Area/Rt* & & \multicolumn{3}{|c|}{ Concentration $\left(40 \mu \mathrm{g} \cdot \mathrm{mL}^{-1}\right)$} \\
\hline 1st day & 2nd day & 3rd day & 1st day & 2nd day & 3rd day \\
\hline 65.114 & 65.442 & 65.548 & 39.866 & 40.071 & 40.138 \\
\hline 65.377 & 64.985 & 64.921 & 40.031 & 39.785 & 39.744 \\
\hline 65.575 & 65.248 & 65.084 & 40.155 & 39.949 & 39.847 \\
\hline \multicolumn{3}{|l|}{ Mean } & 40.017 & 39.935 & 39.910 \\
\hline \multicolumn{3}{|c|}{ Standard deviation (SD) } & 0.145 & 0.144 & 0.204 \\
\hline \multicolumn{3}{|c|}{ Coefficient of variation (CV) } & 0.363 & 0.360 & 0.512 \\
\hline \multicolumn{3}{|c|}{$95 \%$ confidence interval } & 0.361 & 0.357 & 0.507 \\
\hline \multicolumn{6}{|c|}{ ACCURACY RESULTS } \\
\hline \multicolumn{3}{|c|}{ Area/Rt* } & \multicolumn{3}{|c|}{ Concentration } \\
\hline $15 \mu \mathrm{g} \cdot \mathrm{mL}^{-1}$ & $30 \mu \mathrm{g} \cdot \mathrm{mL}^{-1}$ & $45 \mu \mathrm{g} \cdot \mathrm{mL}^{-1}$ & $15 \mu \mathrm{g} \cdot \mathrm{mL}^{-1}$ & $30 \mu \mathrm{g} \cdot \mathrm{mL}^{-1}$ & $45 \mu \mathrm{g} . \mathrm{mL}^{-1}$ \\
\hline 25.223 & 49.304 & 73.088 & 14.825 & 29.941 & 44.871 \\
\hline 25.372 & 49.455 & 73.710 & 14.918 & 30.036 & 45.262 \\
\hline \multirow[t]{6}{*}{25.694} & 49.356 & 73.115 & 15.121 & 29.974 & 44.888 \\
\hline & & & & Recovery $\%$ & \\
\hline & & & $15 \mu \mathrm{g} \cdot \mathrm{mL}^{-1}$ & $30 \mu \mathrm{g} \cdot \mathrm{mL}^{-1}$ & $45 \mu \mathrm{g} . \mathrm{mL}^{-1}$ \\
\hline & & & 98.835 & 99.804 & 99.714 \\
\hline & & & 99.456 & 100.120 & 100.581 \\
\hline & & & 100.806 & 99.912 & 99.751 \\
\hline Recovery \% (me & & & 99.699 & 99.946 & 100.015 \\
\hline Difference $\%$ & & & 0.301 & 0.054 & 0.015 \\
\hline Standard Devia & & & 1.008 & 0.160 & 0.490 \\
\hline Coefficient of $v$ & $\mathrm{n}(\mathrm{CV})$ & & 1.011 & 0.160 & 0.490 \\
\hline Standard Error & & & 0.582 & 0.093 & 0.283 \\
\hline $95 \%$ confidence & & & 2.504 & 0.398 & 1.218 \\
\hline & & ROBUSTNES & DY RESULT & & \\
\hline Expe & No & Retentio & (RSD \%) & Peak & SD \%) \\
\hline & & & & & \\
\hline & & & & & \\
\hline & & & & & \\
\hline & & & & & \\
\hline & & & & & \\
\hline & & & & & \\
\hline
\end{tabular}

\footnotetext{
*Area/Rt: Normalized peak area ratio.
} 


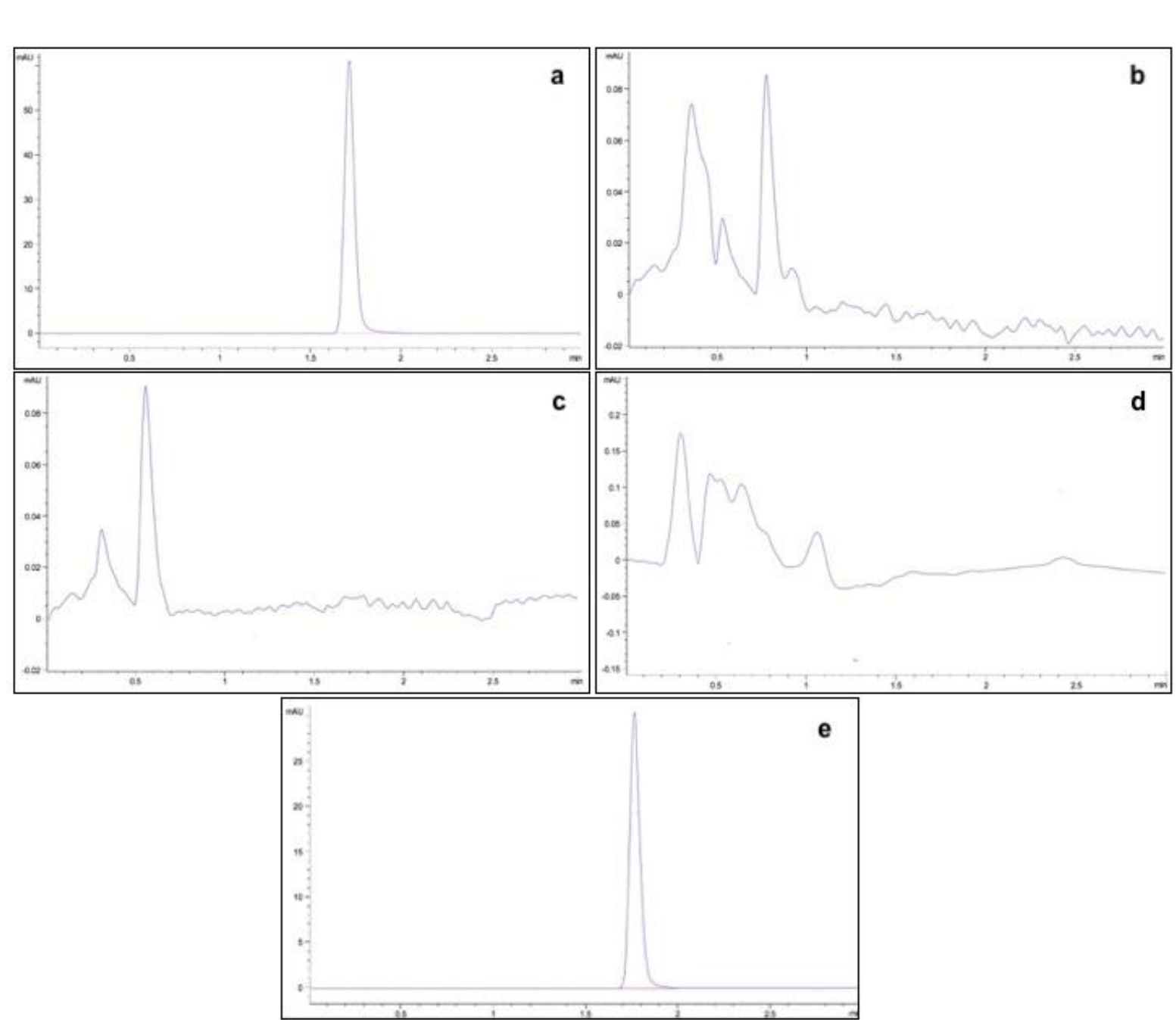

Figure 3. Chromatograms of standard CEF solution, mobile phase, blank microemulsion formulation, $\mathrm{pH}$ 7.4 phosphate buffer and active agent loaded microemulsion formulation.

*a: CEF (standard CEF solution, $250 \mu \mathrm{g} \cdot \mathrm{mL}^{-1}$ ) , b: mobile phase c: blank formulation d: $\mathrm{pH} 7.4$ phosphate buffer e: active agent loaded microemulsion formulation (1:20 dilution in mobile phase)

The pseudo-ternary phase diagrams of microemulsions with four different surfactants: co-surfactant ratios $(\mathrm{Km})$ are shown in Figure 4. The maximum area was found to be Figure $4 / \mathrm{b}(\mathrm{set} 2)$. The clear microemulsion region is presented in phase diagrams. No distinct conversion from water-in-oil (w/o) to oilin-water $(\mathrm{o} / \mathrm{w})$ microemulsions was observed. The rest of the region on the phase diagram represents the turbid and conventional emulsions based on visual observation. The area of microemulsion isotropic region changed slightly in size with the changing ratio of surfactants: co-surfactant. Many previous studies have been observed similar changes. [23,24,25]. Microemulsion formulations for further studies were selected from the weight center of these pseudo-ternary diagrams. Figure 4/e shows the relative areas of microemulsion existence field as a function of $\mathrm{Km}$. The drug-loaded microemulsions were selected from the phase diagram at $\mathrm{Km}$ of 3:1 (Fig 4/b). Because, these ratios are biggest microemulsion area and the most stable after the formation of microemulsions.

Phase transitions are known to occur in microemulsion microstructures as a result of changes in $\mathrm{pH}$, temperature, dilution, etc. At the same time, phase balance and structural phase transformations within active agent loaded microemulsions are of high significance in drug delivery [26,27]. No phase change was observed as a result of heating, cooling, centrifugation and stability studies applied to the formulation. In one study, the $\mathrm{w} /$ o type microemulsion formulation was designed using the surfactant Tween 80, Span 20. As a result of the study, it has been concluded that hydrophilic drugs can be applied with transdermal route and their penetration properties increase [28]. It is predicted that $\mathrm{w} / \mathrm{o}$ microemulsion prepared with water soluble CEF will show promising results in terms of increased penetration when applied with transdermal route. 

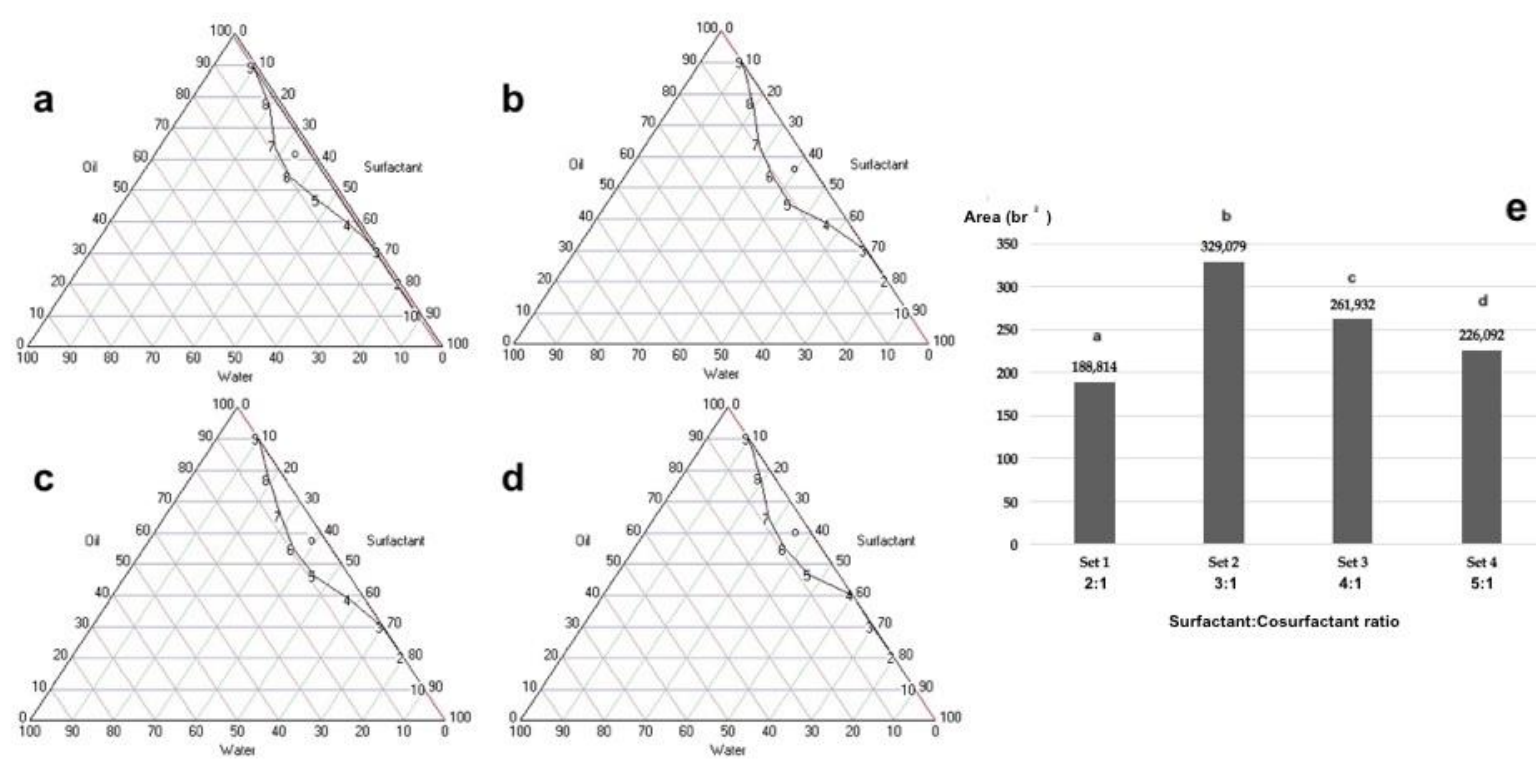

Figure 4. Pseudo-ternary phase diagrams of microemulsions *surfactants:cosurfactant ratio a: 2:1, b: 3:1, c: 4:1, d: 5:1, e: Relative areas of the microemulsion existence field as function of surfactants:cosurfactant ratio.

\subsection{Characterization and six-month stability study of microemulsion formulation}

\subsubsection{Droplet size and polydispersity index (PDI)}

The physical properties of blank formulation and active agent loaded CEF-ME coded formulation are listed in Table 4. Before starting the droplet size and PDI measurement, microemulsion formulations were visually evaluated macroscopically. The prepared dispersion systems were macroscopically identical, homogeneous and transparent without any precipitation. The droplet size of the blank formulation and CEFME coded formulation were measured as $170.6 \mathrm{~nm}$ and $174.4 \mathrm{~nm}$, respectively. The droplet size distribution (PDI) of the blank formulation and CEF-ME coded formulation were observed as 0.154 and 0.150 , respectively. PDI value which defines droplet size distribution is in the range of 0.01 and $0.5-0.7$ for monophasic systems; value higher than 0.7 are indicative of a very wide droplet size distribution and the value close to zero means narrow droplet size distribution [29]. According to this information; it is clear that the formulations prepared are monodisperse. The droplet size of the microemulsion is one of the most important parameters affecting the percutaneous absorption of the drug active substance. When the droplet size is too small, there is a possibility that the topical administration of the microemulsion formulation will increase the efficacy of percutaneous administration, with the number of vesicles that may interact with the stratum corneum in a continuous area [30]. According to this information, the CEF-ME coded formulation prepared in this study is likely to have high percutaneous absorption. When the particle size and distribution parameters are evaluated in the stability study, there was no significant difference $(p>0.05)$ at the $1^{\text {st }}, 2^{\text {nd }}, 3^{\text {rd }}$ and $6^{\text {th }}$ month for both parameters. The difference was obtained by comparing with the measured at zero time. It can be said that the CEF-ME coded formulation, which was prepared when both droplet size and distribution parameters were evaluated, remained stable for 6 months.

\subsection{2. $p H$ determination}

The $\mathrm{pH}$ values of the CEF-ME coded formulation, which is prepared and placed in stability cabinet, are presented in Table 4 . One of the conformity parameters of topically prepared formulations is the $\mathrm{pH}$ measure. It is desirable that the $\mathrm{pH}$ of the formulation is suitable for the skin $\mathrm{pH}$ value and not exhibit any reaction to the skin. The $\mathrm{pH}$ of CEF-ME coded formulation was found near to the skin $\mathrm{pH}$, that showed the microemulsion formulation suitable for skin [15]. In the stability study, there was no significant difference in $\mathrm{pH}$ compared to zero time ( $p>0.05)$. This indicates that the formulation prepared was stable for 6 months for $\mathrm{pH}$. 
Table 4. The physical properties of prepared formulation.

\begin{tabular}{|c|c|c|c|c|}
\hline & Droplet size $(\mathrm{nm})$ & PDI & $\mathrm{pH}$ & Drug content $(\%)$ \\
\hline Blank formulation & $170.6 \pm 2.4$ & $0.154 \pm 0.002$ & $6.42 \pm 0.01$ & - \\
\hline CEF-ME & $174.4 \pm 3.1$ & $0.150 \pm 0.005$ & $6.51 \pm 0.03$ & $99.76 \pm 0.45$ \\
\hline CEF-ME (1st month) & $176.4 \pm 2.7$ & $0.152 \pm 0.003$ & $6.49 \pm 0.02$ & $99.79 \pm 0.30$ \\
\hline CEF-ME (2nd month) & $178.1 \pm 1.5$ & $0.151 \pm 0.002$ & $6.52 \pm 0.03$ & $100.01 \pm 0.12$ \\
\hline CEF-ME (3rd month) & $178.8 \pm 2.4$ & $0.152 \pm 0.008$ & $6.50 \pm 0.08$ & $99.68 \pm 0.54$ \\
\hline CEF-ME (6 ${ }^{\text {th }}$ month) & $177.2 \pm 3.8$ & $0.153 \pm 0.002$ & $6.49 \pm 0.06$ & $99.54 \pm 0.40$ \\
\hline
\end{tabular}

*data: Mean \pm SD

\subsubsection{Drug content}

In the CEF-ME coded formulation, the drug content was found to be in the range of $99.54-100.01 \%$ indicating the homogeneity of high drug content. The drug content results of the microemulsion formulation are shown in Table 4. The formulation, which maintains its stability in parameters such as $\mathrm{pH}$ and droplet size over a 6-month period, ruled its stability in terms of drug content. No significant difference was achieved in terms of the drug according to the first time $(p>0.05)$.

\subsubsection{Rheology}

Rheology examination is one of the important analysis methods for microemulsions. The 'Newtonian flow' model, one of the rheological flow models, has a linear correlation between shear stress and shear rate. The microemulsion system should show low viscosity and Newtonian flow. The conformity of the microemulsion to this flow pattern indicates that the droplets are spherical, do not form an aggregate, the internal phase volume ratio is low and the droplet size is too small [31]. The rheological results of the microemulsions prepared in this study are presented in Figure 5. Figure 5 also shows the results of the stability study. Figure 5 shows that, when measured in the shear rate range of $0-300 \mathrm{sc}^{-1}$, the shear rate and the shear stress increase proportionally to the newton flow type. The prepared formulation showed the newton flow type as a result of the 6-month stability study.

Figure 5. Rheological measurements results.

*0. time measurements:

a: Blank formulation,

b: CEF-ME.

**Stability study:

c: CEF-ME (day 0),

d: CEF-ME (day 15),

e: CEF-ME ( $1^{\text {st }}$ month $)$,

f: CEF-ME ( $2^{\text {nd }}$ month),

g: CEF-ME (3rd month)

h: CEF-ME (6 $6^{\text {th }}$ month).
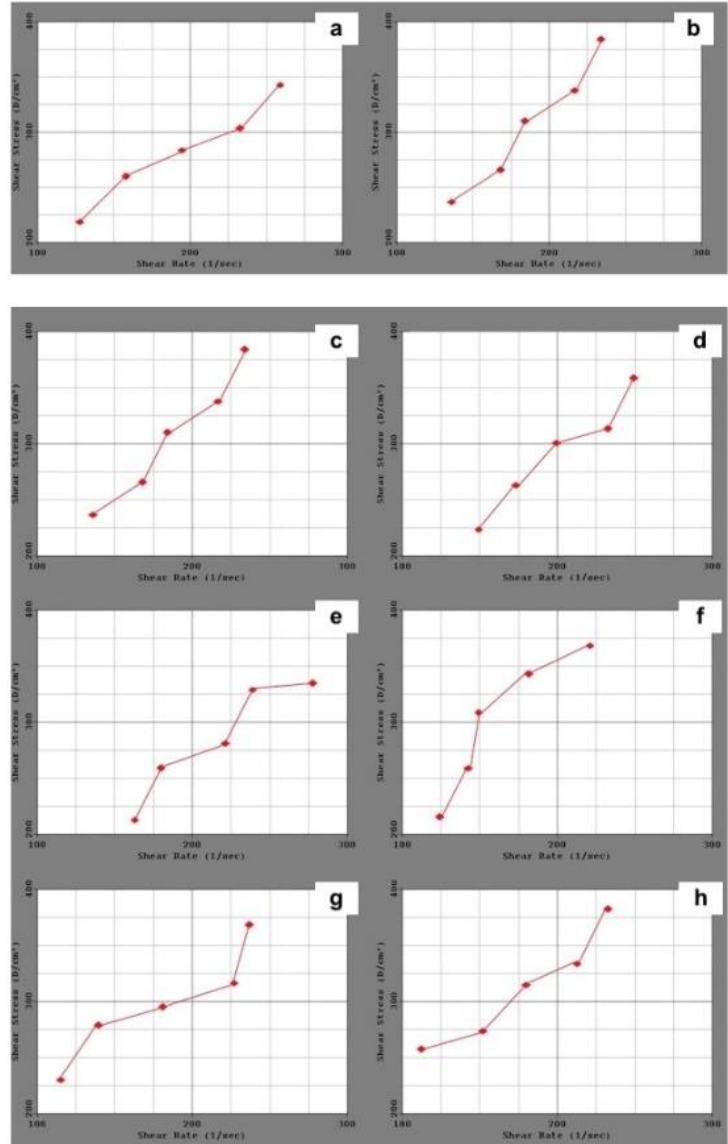


\subsubsection{FT-IR}

In the microemulsion system, FT-IR analysis was performed to determine whether the structure maintained its stability, to investigate phase change or interactions between components. The results of FTIR analysis are shown in Figure 6. In the FT-IR analysis of the CEF-ME coded formulation, no signal was observed to demonstrate interaction between IPM and CEF. In addition, the specific peaks of IPM were preserved and no significant change was observed in the peak intensity of CEF. There was no significant difference in the peak morphology and signals in the FT-IR spectrum even at the end of the $6^{\text {th }}$ month. This shows that the CEF-ME coded formulation preserves the structural stability for 6 months $[32,33]$.

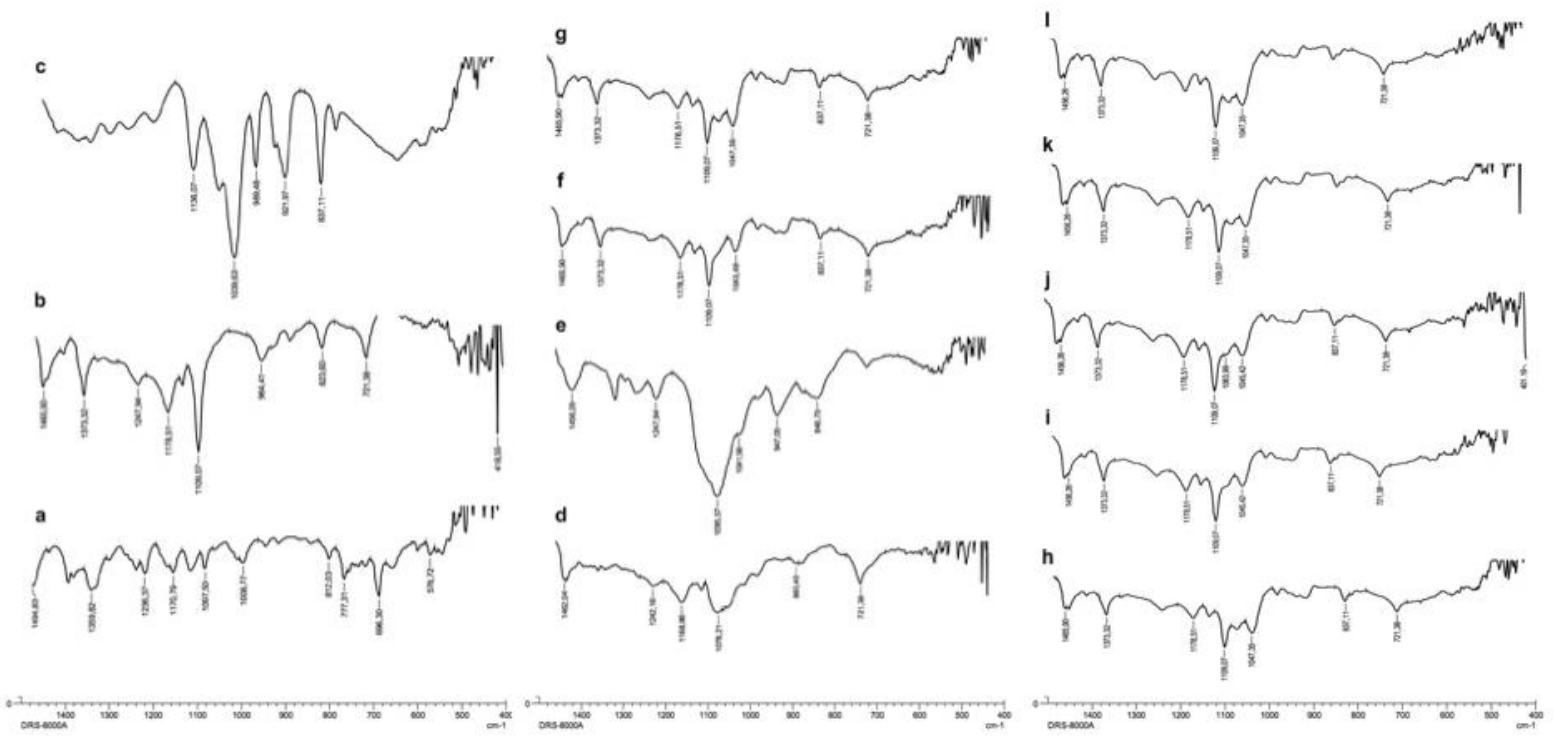

Figure 6. FT-IR analysis result.

**0. time measurements a: CEF b: IPP c: Propylene Glycol d: Span 80 e: Tween $80 \mathrm{f}$ : Blank formulation g: CEF-ME *Stability study h: CEF-ME (day 0) i: CEF-ME (1 ${ }^{\text {st }}$ month), j: CEF-ME (2nd month), k: CEF-ME (3rd month) 1: CEF-ME (6 $6^{\text {th }}$ month)

\subsubsection{In vitro dissolution study}

The in vitro dissolution study of CEF-ME coded formulation were compared with the dissolution profile of the pure CEF. The cumulative release percentages at regular time were calculated and showed in Figure 7. It was determined that the release rate of pure CEF reached $97.1 \% \pm 0.9$ (Mean $\pm S D$ ) within 2 hours. This is due to the fact that the CEF is highly soluble in water. As seen in Figure 7, the amount of CEF released from pure CEF in a pH 7.4 medium was almost complete in 2 hours, whereas that of CEF released from the CEF-ME coded microemulsion formulation is no more than $17.3 \pm 4.6 \%$ (MeaN $\pm \mathrm{SD}$ ). In this study, sustained release was observed for 10 hours and the release of CEF from the formulation prepared at the end of the 10th hour reached $95.2 \pm 5.1 \%$. The results suggest that formulations prepared according to pure CEF have sustained release. The sustained release of this formulation is consistent with the literature [20, 21, 24].

\subsubsection{Release kinetics}

When CEF-ME coded formulation was analyzed for cumulative release in time versus time, formulation appeared to be continuously released for 10 hours. After calculation, the data is transferred to the DDSolver program to determine five important and the most popular criteria. These criteria are based on the coefficient of determination (Rsqr, $R^{2}$, or COD), the adjusted coefficient of determination (Rsqr_adj or $R^{2}$ adjusted), the Akaike Information Criterion (AIC), the Model Selection Criterion (MSC) and $\mathrm{n}$ for only Korsmeyer-Peppas models. The highest $\mathrm{R}^{2}, \mathrm{R}^{2}$ adjusted and MSC values and the lowest AIC values are used for the evaluation [15, 29]. Zero-order kinetic, First-order kinetic, Higuchi, Korsmeyer-Peppas and Hopfenberg models were selected for evaluation in DDSolver program. As a result of applying in vitro release study data obtained to different kinetic models using DDSolver program; $\mathrm{R}^{2}, \mathrm{R}^{2}$ adjusted, MSC, AIC and $\mathrm{n}$ found are shown in Table 5. From the microemulsion formulation (CEF-ME), the release of CEF had zero-order kinetics according to the criterion. This rate of release is preferred because the drug is given in a constant rate for a long time [15]. Similar results are found in the literature [34]. 


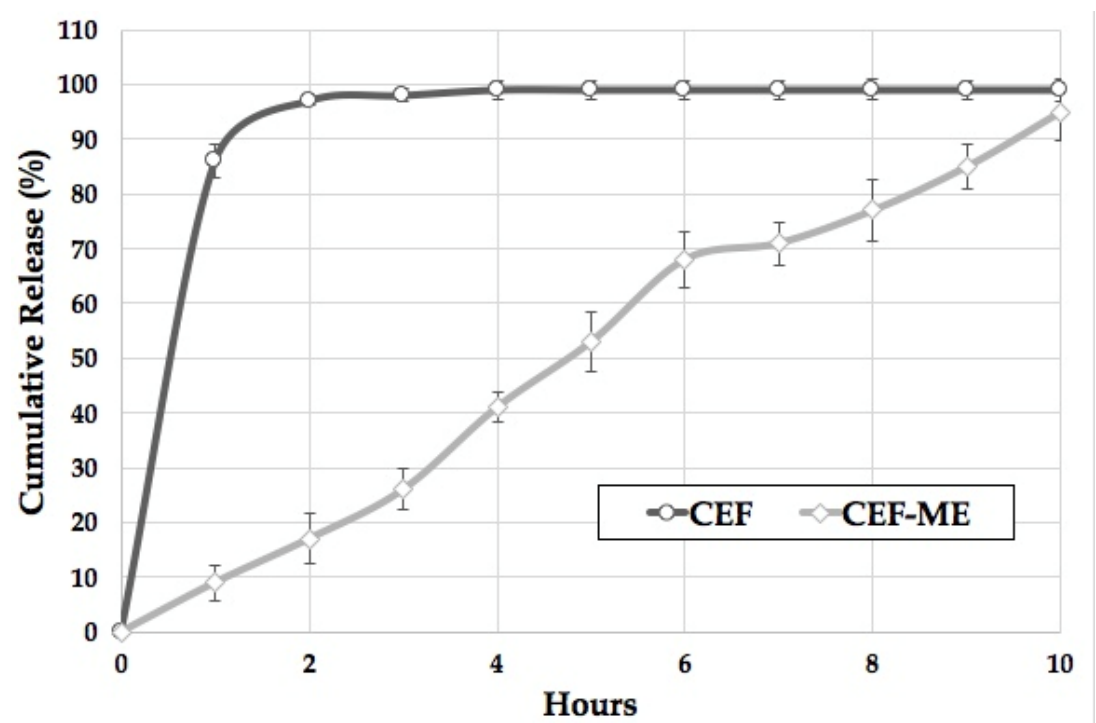

Figure 7. In vitro dissolution study results.

Table 5. Kinetic modeling of microemulsion formulation by DDSolver program.

\begin{tabular}{|c|c|c|c|c|c|c|}
\hline \multirow{2}{*}{ Code } & \multirow{2}{*}{ Model and Equation } & \multicolumn{5}{|c|}{ Evaluation Criter } \\
\hline & & $R^{2}$ & $R^{2}$ adjusted & AIC & MSC & $\mathbf{n}$ \\
\hline CEF-ME & $\begin{array}{c}\text { Zero-order model }^{*} \\
F=k_{0} * t\end{array}$ & 0.986 & 0.986 & 57.070 & 3.829 & - \\
\hline CEF-ME & $\begin{array}{l}\text { First-order model }^{*} \\
F=100^{*}\left(1-e^{-k 1^{*} t}\right)\end{array}$ & 0.933 & 0.933 & 74.366 & 2.257 & - \\
\hline CEF-ME & $\begin{array}{c}\text { Higuchi model } \\
F=k_{\mathrm{H}} * 0.5\end{array}$ & 0.866 & 0.866 & 81.897 & 1.572 & - \\
\hline CEF-ME & $\begin{array}{c}\text { Korsmeyer-Peppas* } \\
F=k_{\mathrm{KP}}^{*} t^{n}\end{array}$ & 0.984 & 0.982 & 60.865 & 3.483 & 0.936 \\
\hline CEF-ME & $\begin{array}{l}\text { Hopfenberg Model } \\
F=100^{*}\left[1-\left(1-k_{H B}{ }^{*} t\right)^{n}\right]\end{array}$ & 0.986 & 0.984 & 59.070 & 6.648 & 1.000 \\
\hline
\end{tabular}

*In all models, $\boldsymbol{F}$ is the fraction (\%) of drug released in time $\mathbf{t}, \boldsymbol{k}_{0}$ : zero-order release constant, $\boldsymbol{k}_{1}$ :first-order release constant, $k_{\mathrm{H}}$ : Higuchi release constant, $k_{\mathrm{HB}}$ : Hopfenberg release constant, $\boldsymbol{k}_{\mathrm{KP}}$ : release constant incorporating structural and geometric characteristics of the drug-dosage form, $n$ : is the diffusional exponent indicating the drug-release mechanism.

\section{CONCLUSION}

In this study, an UPLC method for the simultaneous determination of cefaclor monohydrate was developed and validated. Proposed method is the first reported UPLC method that enables the analysis of cefaclor monohydrate. Method validation studies for cefaclor monohydrate were carried out according to the ICH guideline Q2 (R1). The method developed was validated for linearity, specificity, precision, sensitivity, accuracy, range and robustness. In the second phase of the study, cefaclor monohydrate loaded microemulsion formulation was prepared for the topical application. Microemulsion characterization studies and 6-month stability studies have shown that the prepared formulation is physically and chemically stable and is a promising system for topical application. Further studies will be focused on the in vivo animal studies and tissue distribution in order to get a proper insight into the potential of microemulsion formulations in topical delivery.

\section{MATERIALS AND METHODS}

\subsection{Materials}

CEF was obtained from Sanovel (Istanbul/Turkey) as a gift sample. All the other chemicals and reagents used were of analytical grade.

\subsection{Method development and optimization}

Different methods with varying parameters were tested for best resolution, peak shape, and minimum \& acceptable retention time at every single day for the condition of the device. UPLC device (Agilent 
Technology 1290 Infinity) used was mounted with reversed-phase (RP) Zorbax Eclipse Plus $\mathrm{C}_{18}$ gravity column (column length: $50 \mathrm{~mm}$, column diameter: $2.1 \mathrm{~mm}$, particle diameter: $1.8 \mu \mathrm{m}) .40: 50: 10(\mathrm{v} / \mathrm{v} / \mathrm{v})$ methanol: water: $0.1 \mathrm{M}$ acetate buffer was used as the mobile phase for perfect resolution of CEF. Flow rate of the mobile phase was set at $0.25 \mathrm{~mL} \cdot \mathrm{min}^{-1}$ and $0.5 \mu \mathrm{L}$ invariable volume of specimen were injected by an automatic injector. Temperature of the column was set to $40{ }^{\circ} \mathrm{C}$ while a fluorescent detector was used at 265 nm.

\subsection{Method validation}

\subsubsection{Linearity and range}

Aliquots from a standard stock solution $\left(250 \mu \mathrm{g} \cdot \mathrm{mL}^{-1}\right)$ of CEF were used to prepare different sets of dilutions. A series of dilutions consisted of 6 different concentrations of CEF in the range of 5-55 $\mu \mathrm{g} \cdot \mathrm{mL}^{-1}$. Absorbance values were measured and calculations were made to determine CEF concentration. Quantification was accomplished on the basis of CEF normalized peak area ratios (rPN) [(rPN: peak area of $\mathrm{CEF} /$ retention time of CEF); Briefly (Area/Rt)].

\subsubsection{Limit of detection and limit of quantitation (sensitivity)}

Limit of Detection (LOD) and Limit of Quantitation (LOQ) were separately determined based on the calibration curve obtained according to ICH Q2 (R1) recommendations (Eq. 1, Eq. 2). Standard deviation of yintercept and slope of the calibration curve were used to calculate LOD and LOQ, respectively.

$$
\begin{aligned}
& \mathrm{LOD}=3.3 \times \sigma / \mathrm{S} \\
& \mathrm{LOQ}=10 \times \sigma / \mathrm{S} \\
& { }^{*} \sigma=\text { the standard deviation of the response and } \mathrm{S}=\text { slope of the calibration curve. }
\end{aligned}
$$

\subsubsection{Precision}

Intermediate precision and repeatability values when using the device in this study was verified by repeated scanning and measurement of absorbance's $(\mathrm{n}=6)$ for CEF $\left(20 \mu \mathrm{g} \cdot \mathrm{mL}^{-1}, 30 \mu \mathrm{g} \cdot \mathrm{mL}^{-1}, 40 \mu \mathrm{g} \cdot \mathrm{mL}^{-1}\right)$. Repeatability studies were performed six times on the same day by analyzing three different concentrations of $20 \mu \mathrm{g} \cdot \mathrm{mL}^{-1}, 30 \mu \mathrm{g} \cdot \mathrm{mL}^{-1}, 40 \mu \mathrm{g} \cdot \mathrm{mL}^{-1}$ for CEF. Repeating tests on three consecutive days verified intermediate precision of the method. Results were expressed as RSD\% of the measurements obtained.

\subsubsection{Accuracy}

Accuracy of the method used was determined by calculating recoveries of CEF by standard addition method. Standard solutions containing specific amount of CEF $\left(15 \mu \mathrm{g} \cdot \mathrm{mL}^{-1}, 30 \mu \mathrm{g} \cdot \mathrm{mL}^{-1}, 45 \mu \mathrm{g} \cdot \mathrm{mL}^{-1}\right)$. were used and percentage of recoveries were calculated.

\subsubsection{Robustness}

Robustness is the measure of the analytical method's ability to remain unaffected by small changes in method parameters. The factors chosen for this Robustness study were the wavelength $(\mathrm{nm})$, temperature $\left({ }^{\circ} \mathrm{C}\right)$, flow $\left(\mathrm{mL} \cdot \mathrm{min}^{-1}\right)$. The factors are shown in Table 6.

Table 6. Experimental design of the robustness study.

\begin{tabular}{cccc}
\hline Experiment No & Wavelength $(\mathbf{n m})$ & Temperature $\left({ }^{\circ} \mathbf{C}\right)$ & Flow $\left(\mathbf{m L . m i n}^{-1}\right)$ \\
\hline $\mathbf{1}$ & 265 & 38 & 0.25 \\
$\mathbf{2}$ & 265 & 38 & 0.22 \\
$\mathbf{3}$ & 263 & 40 & 0.22 \\
$\mathbf{4}$ & 263 & 40 & 0.25 \\
$\mathbf{5}$ & 265 & 40 & 0.22 \\
$\mathbf{6}$ & 263 & 38 & 0.25 \\
\hline
\end{tabular}

\subsubsection{Specificity}

The specificity of the UPLC method was determined by complete separation of the CEF with the mobile phase, $\mathrm{pH}$ 7.4 phosphate buffer used in the in vitro dissolution study, and then the effect of the excipients used in the microemulsion formulation was investigated with blank formulations to determine whether or not the interfered. 


\subsection{Construction of pseudo-ternary phase diagrams}

In order to find out the concentration ranges of components in microemulsion, pseudo-ternary phase diagrams were constructed using water titration method at room temperature $\left(25^{\circ} \mathrm{C}\right)$. In the microemulsion systems, isopropyl myristate (IPM), polyoxyethylene sorbitan monooleate (Tween 80), sorbitan monoester (Span 80) and propylene glycol were selected as an oil component, surfactants and co-surfactant, respectively. The surfactants (3:1 mixture of Span 80 and Tween 80) were prepared separately. All microemulsions were formulated with double distilled water to prevent from surface-active impurities.

The weight ratio of surfactant mixed to cosurfactant varied as 2:1, 3:1, 4:1, and 5:1. For each pseudoternary phase diagram, mixtures of IPM and surfactants/co-surfactant mixtures were prepared at weight ratios of 1:9, 2:8, 3:7, 4:6, 5:5, 6:4, 7:3, 8:2 and 9:1 respectively. The mixtures of oil, surfactants and co-surfactant at certain weight ratios were diluted with drop wise addition of double distilled water under moderate mechanical stirring $(500 \mathrm{rpm})$ until the mixture became clear at a certain point. The concentration of components was recorded in order to complete the pseudo-ternary phase diagram.

\subsection{Preparation of CEF loaded microemulsions}

Microemulsion formulations selected from the constructed pseudo-ternary phase diagrams were prepared according to the composition presented in Table 7. The CEF loaded microemulsion formulations were selected at different component ratios. Microemulsion systems were obtained by mixing oil, surfactants and cosurfactant together, and adding identified water drop by drop to these oily phases with mechanical stirring at room temperature $\left(25^{\circ} \mathrm{C}\right)$. The active substance was first dissolved in water. Formulations were prepared by adding this solution dropwise to the system. The final concentration of CEF in microemulsion systems was $0.25 \%(\mathrm{w} / \mathrm{w})$.

Table 7. Composition of various microemulsion formulations.

\begin{tabular}{lllll}
\hline \multicolumn{5}{l}{ Formulation Code (\% weight) } \\
\hline Composition & CEF-ME (2:1) & CEF-ME (3:1) & CEF-ME (4:1) & CEF-ME (5:1) \\
IPM & 62.248 & 56.521 & 57.906 & 60.761 \\
Tween 80 & 5.563 & 7.301 & 7.748 & 7.476 \\
Span 80 & 16.688 & 22.004 & 23.245 & 22.429 \\
Propylene gylcol & 11.126 & 9.752 & 7.748 & 5.981 \\
Water & 4.375 & 4.172 & 3.354 & 3.353 \\
CEF & 0.250 & 0.250 & 0.250 & 0.250 \\
\hline
\end{tabular}

\subsection{Characterization of microemulsion formulation}

\subsubsection{Droplet size and Polydispersity Index (PDI)}

The droplet size and PDI were measured using dynamic light scattering technique (DLS) on the Zetasizer Nano (Zetasizer Nano ZS, Malvern Instruments, Malvern, UK) by without dilution. All samples were analyzed in triplicates.

\subsection{2. $\mathrm{pH}$ determination}

The $\mathrm{pH}$ of the CEF loaded microemulsion was determined using digital $\mathrm{pH}$ meter (Mettler Toledo ${ }^{\mathrm{TM}}$ S220 Seven Compact ${ }^{\mathrm{TM}} \mathrm{pH} /$ lon Benchtop Meter). The measurements were taken for average of 3 times.

\subsubsection{Drug content}

The content of microemulsion formulation was determined by dispersion of $1 \mathrm{~mL}$ of microemulsion in $20 \mathrm{~mL}$ of mobile phase. Microemulsion formulation diluted with mobile phase was filtered through $0.22 \mu \mathrm{m}$ polyamide filter and analyzed using UPLC.

\subsubsection{Rheology}

Rheological properties were determined using a cone-and-plate geometry rheometer with a diameter of $40 \mathrm{~mm}$ (Brookfield, USA). Measurements and viscosity changes were repeated at $25 \pm 1^{\circ} \mathrm{C}$ temperatures. 
Shear rates against shear stress were calculated. Measurements provide further information about flow properties.

\subsubsection{FT-IR}

FT-IR spectra were recorded using Shimadzu IR Prestige-21 (Shimadzu Corporation, Kyoto, Japan) at the wavelength range of 4000-500 $\mathrm{cm}^{-1}$. Pure CEF, IPP, propylene glycol, Tween 80 and Span 80 and blank formulation were also analyzed and were used as references.

\subsubsection{In vitro dissolution study}

In vitro release of $\mathrm{CEF}$ from microemulsion formulation was investigated over 10 hours using a dialysis membrane. $1 \mathrm{~mL}$ CEF loaded microemulsion was placed in a cellulose acetate dialysis bag (Dialysis tubing cellulose membrane avarage flat width $33 \mathrm{~mm}$ [1.3 in.], molecular weight cut-off [MWCO]:14,000, D9652, Sigma-Alrich, USA). After the addition of $1 \mathrm{~mL}$ of microemulsion, the bag was sealed at both ends. Dialysis bag was then placed into an amber glass beaker containing $100 \mathrm{~mL}$ PBS (pH 7.4, Solution prepared with Phosphate buffered saline tablet, P4417, Sigma-Alrich, USA) at $37^{\circ} \mathrm{C} \pm 1^{\circ} \mathrm{C}$ as the dissolution medium under continuous stirring of $50 \mathrm{rpm}$ (MS-33MH Magnetic stirrer, Jeiotech, Korea) [15]. The receptor compartment was closed to prevent evaporation of the dissolution medium. Samples were withdrawn at regular time intervals and the same volume was replaced by fresh dissolution medium. CEF concentration in the samples was quantified by UPLC method.

\subsubsection{Release kinetics}

To determine the release kinetics, data obtained from in vitro drug release studies in phosphate buffer ( $\mathrm{pH}$ 7.4) were analyzed by a software program DDSolver Software program.

\subsection{Six month stability study of microemulsion formulation}

The storage stability of CEF loaded microemulsion was followed to ICH Q1(R2) at $25 \pm 1^{\circ} \mathrm{C} / 60 \pm 5 \%$ relative humidity $(\mathrm{RH})$ up to six-months. In the stability studies; Droplet size, PDI, pH determination, Drug content, Rheology, FT-IR analysis were examined at certain time intervals. The characterizations in stability study were made as described in the upper section.

\subsection{Software program}

Microsoft Excel, GraphPad Prism 6 and DDSolver were employed for calculations.

Acknowledgements: Sanovel (İstanbul, Turkey) for providing cefaclor monohydrate. The authors would also like to thank to Anadolu University, Faculty of Pharmacy, DOPNALAB for FT-IR facilities.

Author contributions: Concept - AAÖ; Design - AAÖ, UMG; Supervision - AAÖ Resource - AAÖ; Materials - AAÖ, UMG; Data Collection and/or Processing. AAÖ, UMG; Analysis and/or Interpretation - AAÖ, UMG; Literature Search - AAÖ, UMG Writing - AAÖ, UMG Critical Reviews - AAÖ, UMG.

Conflict of interest statement: The authors declare no conflict of interest.

\section{REFERENCES}

[1] Ribeiro AR, Sures B, Schmidt TC. Cephalosporin antibiotics in the aquatic environment: A critical review of occurrence, fate, ecotoxicity and removal technologies. Environ Pollut. 2018; 241: 1153-1166. [CrossRef]

[2] Lin CE, Chen HW, Lin EC, Lin KS, Huang HC. Optimization of separation and migration behavior of cephalosporins in capillary zone electrophoresis. J Chromatogr A. 2000; 879:197-210. [CrossRef]

[3] Ray P, Knowlton KF, Shang C, Xia K. Development and validation of a UPLC-MS/MS method to monitor cephapirin excretion in dairy cows following intramammary infusion. 2014; PLoS ONE 9(11): e112343. [CrossRef]

[4] Mohamed MA, Ali AH, Abdelfatah AM, Ahmed MO. Validation and comparative in-vitro dissolution studies of cefaclor in their powder for oral suspension dosage forms. Anal Chem Lett. 2018; 8(1): 88-103. [CrossRef]

[5] Zhao YY, Wu SP, Liu S, Zhang Y, Lin RC. Ultra-performance liquid chromatography-mass spectrometry as a sensitive and powerful technology in lipidomic applications. Chem Biol Interact. 2014; 220: 181-192. [CrossRef] 
[6] Nordström A, O’Maille G, Qin C, Siuzdak G. Nonlinear data alignment for UPLC-MS and HPLC-MS based metabolomics: Quantitative analysis of endogenous and exogenous metabolites in human serum. Anal Chem. 2006; 78: 3289-3295.[CrossRef]

[7] Zhao YY, Lin RC. UPLC-MSE application in disease biomarker discovery: The discoveries in proteomics to metabolomics. Chem Biol Interact. 2014; 215: 7-16.[CrossRef]

[8] JoshiS. HPLC separation of antibiotics present in formulated and unformulated samples. J Pharm Biomed Anal. 2002; 28: 795-809.[CrossRef]

[9] El-Shaboury SR, Saleh GA, Mohamed FA, Rageh AH. Analysis of cephalosporin antibiotics. J Pharm Biomed Anal. 2007; 45(1):1-19. [CrossRef]

[10] Granados-Soto V, Aguilar-Cota ME, Reyes-Garcia G, Medina-Santillán R, Flores-Murrieta FJ. Simple method for the determination of cefaclor in human plasma samples by HPLC. J Liq Chromatogr RelatTechnol. 2003; 26(19): 33153323. [CrossRef]

[11] Lu Y, Wu K, Li L, He Y, Cui L, Liang N, Mu B. Characterization and evaluation of an oral microemulsion containing the antitumor diterpenoid compound ent-11alpha-hydroxy-15-oxo-kaur-16-en-19-oic-acid. Int J Nanomed. 2013; 8: 1879-1886.[CrossRef]

[12] Tang TT, Hu XB, Liao DH, Liu XY, Xiang DX. Mechanisms of microemulsion enhancing the oral bioavailability of puerarin: comparison between oil-in-water and water-in-oil microemulsions using the single-pass intestinal perfusion method and a chylomicron fow blocking approach. Int J Nanomed. 2013; 8: 4415-4426. [CrossRef]

[13] Roberts MS, Mohammed Y, Pastore MN, Namjoshi S, Yousef S, Alinaghi A, Haridass IN, Abd E, Leite-Silva VR, Benson HAE, Grice JE. Topical and cutaneous delivery using nanosystems. J Control Release. 2017; 247:86-105. [CrossRef]

[14] Öztürk AA, Yenilmez E, Yazan Y. Development and validation of high performance liquid chromatography (HPLC) modified method for dexketoprofen trometamol. Eur Int J Sci Tec. 2017;6(5):33-41

[15] Öztürk AA, Güven UM, Yenilmez E. Flurbiprofen loaded gel based topical delivery system: Formulation and in vitro characterization with new developed UPLC method. Acta Pharm Sci. 2018;56(4):81-105. [CrossRef]

[16] Q2(R1) ICH Harmonised Tripartite Guideline (2014). Validation of Analytical Procedures: Text and Methodology.

[17] Uhrovčík J. Strategy for determination of LOD and LOQ values - Some basic aspects. Talanta. 2014;119:178-180 [CrossRef]

[18] Kogan A, Garti N. Microemulsions as transdermal drug delivery vehicles. Adv Col Int Sci. 2006;123:369-385. [CrossRef]

[19] Herman A, Herman AP. Essential oils and their constituents as skin penetration enhancer for transdermal drug delivery: A review. J Pharm Pharmacol. 2015;67(4): 473-485. [CrossRef]

[20] Huang YB, Lin YH, Lu TM, Wang RJ, Tsai YH, Wu PC. Transdermal delivery of capsaicin derivative-sodium nonivamide acetate using microemulsions as vehicles. Int J Pharm. 2008;349(1-2):206-211. [CrossRef]

[21] Goldberg-Cettina M, Liu P, Nightingale J, Kurihara-Bergstrom T. Enhanced transdermal delivery of estradiol in vitro using binary vehicles of isopropyl myristate and short-chain alkanols. Int J Pharm. 1995;114(2):237-245. [CrossRef]

[22] Liu CH, Chang FY, Hung DK. Terpene microemulsions for transdermal curcumin delivery: Effects of terpenes and cosurfactants. Col Surf B: Biointerfaces. 2011; 82(1):63-70. [CrossRef]

[23] Chen H, Chang X, Weng T, Zhao X, Gao Z, Yang Y, Yang X. A study of microemulsion systems for transdermal delivery of triptolide. J Control Release. 2004;98(3):427-436. [CrossRef]

[24] Okur NÜ, Yavaşoğlu A, Karasulu HY. Preparation and evaluation of microemulsion formulations of naproxen for dermal delivery. Chem Pharm Bull. 2014; 62(2): 135-143. [CrossRef]

[25] El Maghraby GM. Transdermal delivery of hydrocortisone from eucalyptus oil microemulsion: Effects of cosurfactants. Int J Pharm. 2008; 355(1-2):285-292. [CrossRef]

[26] Bharti SK, Kesavan K. Phase-transition W/O microemulsions for ocular delivery: Evaluation of antibacterial activity in the treatment of bacterial keratitis. Ocular Immuno Inflam. 2017; 25(4): 463-474. [CrossRef]

[27] Lawrence MJ, Rees GD. Microemulsion-based media as novel drug delivery systems. Adv Drug Del Rev. 2012; 64:175-193. [CrossRef]

[28] Schmalfuss U, Neubert R, Wohlrab W. Modification of drug penetration into human skin using microemulsions. J Control Release. 1997; 46(3): 279-285. [CrossRef] 
[29] Öztürk AA, Martin Banderas L, Cayero Otero MD, Yenilmez E, Yazan Y. New Approach to hypertension treatment: Carvediol-loaded PLGA nanoparticles, preparation, in vitro characterization and gastrointestinal stability. Lat Am J Pharm. 2018; 37(9):1730-1741

[30] Shah RR, Magdum CS, Patil SS, Naikwade NS. Preparation and evaluation of aceclofenac topical microemulsion. Iran J Pharm Res. 2010;9(1):5-11.

[31] Subramanian N, Ghosal SK, Acharya A, Moulik SP. Formulation and physicochemical characterization of microemulsion system using isopropyl myristate, medium-chain glyceride, polysorbate 80 and water. Chem Pharm Bull. 2005; 53(12):1530-1535. [CrossRef]

[32] Öztürk AA, Güven UM, Yenilmez E, Şenel B. effects of different derivatives of eudragit polymer on entrapment efficiency, in vitro dissolution, release kinetics and cell viability results on extended release flurbiprofen loaded nanomedicines. Lat Am J Pharm. 2018;37(10):1981-1992.

[33] Öztürk AA, Yenilmez E, Şenel B, Arslan R, Yazan Y. Dexketoprofen trometamol-loaded Kollidon ${ }^{\circledR}$ SR and Eudragit ${ }^{\circledR}$ RS 100 polymeric nanoparticles: Formulation and in vitro-in vivo evaluation. Lat Am J Pharm. 2017;36(11):2153-2165.

[34] Singh VK, Anis A, Al - Zahrani SM, Pal K. Microemulsions of sorbitans and its derivatives for 1ontophoretic drug delivery. Int J Electrochem Sci. 2015;10:2239-2252.

This is an open access article which is publicly available on our journal's website under Institutional Repository at http://dspace.marmara.edu.tr. 